\title{
Body Mass Index, Practice of Physical Activity and Lifestyle of Students During COVID-19 Lockdown
}

\author{
Sahbanathul Missiriya Jalal \\ Mini Rani Mary Beth \\ Hawraa Jassim Mohammad Al- \\ Hassan
}

Nuriya Mousa Jafar Alshealah

Department of Nursing, College of Applied Medical Sciences, King Faisal University, Al-Ahsa, 31982, Saudi Arabia

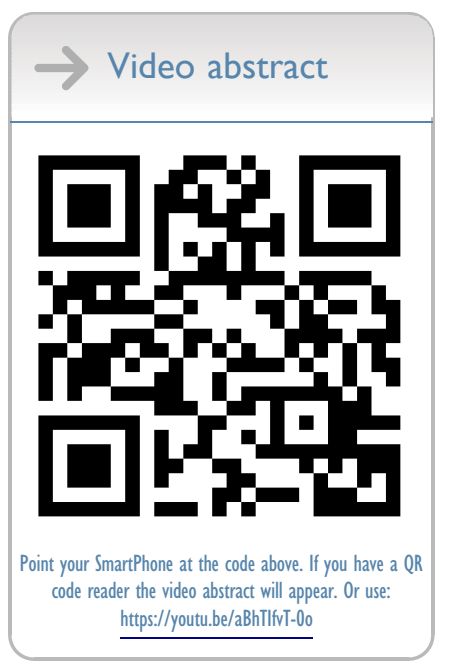

Correspondence: Sahbanathul Missiriya Jalal

Tel +966564070973

Email sjalal@kfu.edu.sa
Purpose: Several factors influence the student's physical activity and lifestyle. The coronavirus disease (COVID-19) lockdown has restricted student's activity and altered their routine lifestyle. This prospective cohort study aimed to determine the significant changes in body mass index (BMI), physical activity, and lifestyle of the students including diet, sleep, and mental health before and during COVID-19 lockdown.

Methods: The study participants were 628 students studying bachelor's degree programs, between 18 and 30 years of age, both genders from the university of Al-Ahsa, Saudi Arabia. The lockdown began on 23 March and ended on 21 June 2020 in Saudi Arabia. The students were interviewed before (March 2020) and during (June 2020) lockdown. The structured tool included baseline information of the students, anthropometric data, global physical activity questionnaire (GPAQ), dietary recall, Pittsburgh sleep quality index (PSQI), and perceived stress scale (PSP). Chi-square tests were used to associate the baseline information with BMI changes during the lockdown.

Results: BMI of the students showed that $32 \%$ increased their weight, $22 \%$ lost their weight and $46 \%$ maintained the same weight during COVID-19 lockdown. The physical activity significantly decreased and sedentary time increased $(p=0.0001)$. Regarding the lifestyle components, fast and fried food consumption decreased, and calorie intake increased significantly $(p=0.001)$. Stress level $(p=0.001)$ significantly decreased, and sleep level $(p=$ $0.001)$ increased during lockdown. The variables associated with weight changes were the level of students $(p<0.05)$ and time spent on social media per day $(p<0.0001)$.

Conclusion: Though half of the students maintained the same BMI during the lockdown, students who increased BMI were associated with physical activity and lifestyle. Hence, health awareness on weight maintenance, active physical activities, and a healthy lifestyle must be created among the students, which help in creating and implementing policies in the future.

Keywords: COVID-19, body mass index, weight changes, physical activity, lifestyle, lockdown

\section{Introduction}

The Coronavirus disease 2019 (COVID-19) pandemic has the potential to cause considerable morbidity and mortality, affecting the people and health care systems globally. ${ }^{1}$ Most of the countries followed restrictive measures such as closing cultural events, prohibiting social events, home confinement, and lockdown to prevent disease transmission and to contain the COVID-19 outbreak. ${ }^{2}$ To prevent the spread of COVID-19, educational institutions were closed, and online education was implemented. Although these restrictive measures decreased the COVID-19 spread, it may also lead to health risk behaviors ${ }^{3}$ and may impact the student's physical activity, dietary 
pattern, sleeping hours, social habits, and mental health. ${ }^{4,5}$ These health-related factors may affect the normal body weight maintenance of college students. ${ }^{6}$

The Kingdom of Saudi Arabia (KSA) announced a series of restrictions due to the increasing number of COVID-19 cases. The lockdown began on 23 March and ended on 21 June 2020 to limit the spread of COVID-19. During the lockdown, people could go out of their houses for necessary shopping from 6 am to $7 \mathrm{pm}$ in the partial lockdown period and 6 am to $3 \mathrm{pm}$ in increased timing of lockdown period. Physical activity ${ }^{7}$ has been reduced for students because of lockdown movements; this could alter their BMI. One of the common primary contributors to the obesity or overweight epidemic is physical inactivity, which could be promoted or delayed by various environmental factors. ${ }^{8}$

Globally, the prevalence of obesity has risen, reaching pandemic levels. It requires methods that combine individual interventions with environmental and societal changes to decrease obesity prevalence. ${ }^{9}$ The leading risk factors in the world for cardiovascular diseases are sedentary lifestyles and physical inactivity. Cardiorespiratory fitness could be achieved by improving physical activity, and healthy lifestyle practices. ${ }^{10}$

Evidence indicated that increased BMI status is highly related to developing severe complications of COVID19. ${ }^{11,12}$ The changes in body weight, either obesity or underweight are proven to be important health-related risk factors for various pathologies, including COVID-19. ${ }^{13}$ Research proved that both obesity and food insecurity are common public health concerns that usually influences at the individual and environmental levels. Food insecurity has been associated with weight gain and the risk of obesity. ${ }^{14-16}$

Lifestyle components such as physical inactivity, sedentary lifestyle practices, and dietary habits are the main factors influencing the maintenance of BMI and contributing to obesity among adolescents and young adults, which was evidenced from several research studies. ${ }^{17}$ The key factors contributing to obesity among college students are dietary habits, which include dietary consumption patterns, frequency of meals, and skipping breakfast. ${ }^{18}$ Furthermore, lockdown policies disrupted the student's habits and lifestyles. ${ }^{19}$

A study on the direction of the association between body fatness and self-reported screen time in Dutch adolescents resulted in that time spent watching television predicted changes in body mass index. Computer utilization time was significantly predicted to increase skinfolds in boys and girls and BMI in girls alone. ${ }^{20}$ Body fatness did not predict any variation in screen time. ${ }^{21}$ Other studies also indicated that the frequency of meal intake contributed to the development of obesity. ${ }^{22,23}$ Another study result revealed that half of Brits (47\%) had put on weight since their nation started in lockdown. Despite the severity and health consequences of the COVID-19 outbreak is instigating wider conversations around the nation's health as well as the importance of a balanced lifestyle. ${ }^{24-27}$

The lack of weight management activities and unhealthy dietary practices were more common among students and it might have worsened due to the COVID19 lockdown in Saudi Arabia which is alarming the risk factors and increasing obesity rate. ${ }^{28}$ Evidences showed that the poor sleep quality among students was very high in COVID-19 lockdown and that altered sleep might have resulted in lifestyle changes. This has been associated with behavioral changes, dietary changes, and BMI. $^{29}$ University students were particularly susceptible to experiencing mental health problems comparing with the general population. ${ }^{30}$ Therefore, we conducted this study to test the hypothesis, in which the primary aim of the study was to determine the changes in BMI status, physical activity, and lifestyle of the students including diet, sleep, and mental health of the university students before and during the COVID-19 lockdown. The secondary aim was to associate the baseline information of the students and parameters with the changed status of BMI.

\section{Materials and Methods Study Design}

A prospective cohort research design with a survey approach was conducted among the university students at two points, once in before lockdown (March 2020) and another once during lockdown (June 2020), of the pandemic. The study was conducted according to the guidelines of Helsinki and ethically approved by the Research Ethics Committee, Deanship of Scientific Research at King Faisal University (HAPO-05-HS-003). Informed consent was obtained from all subjects involved in the study before data collection and ensured confidentiality, no risk, anonymity, and voluntary participation.

\section{Study Setting and Participants}

The study was carried out at Al-Ahsa which is the largest governorate in the eastern province of Saudi Arabia. There are many educational organizations available. There, 
21,870 students were studying at the graduate courses in various disciplines such as medical, health, science, and arts. The calculation of sample size was determined by using the open-source epidemiologic statistics from the website of public health. From the total undergraduate students, the estimated sample size was 642 with a $95 \%$ confidence level and $80 \%$ power. The students of graduate programs were selected from their registration numbers by using a simple random technique with the assistance of computerized generation software. However, finally, from those selected participants, 628 students responded to the data collection.

\section{Data Collection}

The structured tool included baseline information of the students, anthropometric data, global physical activity questionnaire (GPAQ), dietary recall, Pittsburgh sleep quality index (PSQI), and perceived stress scale (PSP).

\section{Baseline Information}

Participated students were interviewed for baseline information such as age in years, gender, level of study, marital status, family type, and time spent in social media per day during the initial point of data collection.

\section{Anthropometric Data}

The body weight and height of the students were measured in college during the first point of an interview before lockdown. Students were asked to wear light clothes. From which measurements, BMI was calculated. During the lockdown, students were asked to check their weight in their residence two times in the early morning with their light clothes at the second point of data collection. BMI was calculated by using the mean weight of two measures stated by them. The BMI classifications ${ }^{31}$ as per National Institute of Health (NIH) and the World Health Organization (WHO) recommendations were used. From the BMI calculated at two points of time, the changes were determined to have increased or decreased BMI. If there were no changes, it was considered as stable BMI. ${ }^{32}$

\section{Physical Activity Questionnaire}

The GPAQ ${ }^{33}$ developed by the World Health Organization (WHO) was used to assess the practice of physical activity $^{34}$ of the students in both points as before and during the lockdown. This questionnaire has four domains such as moderate and vigorous activity at work, travel to and from places, moderate and vigorous recreational activities, and sedentary behavior. In that, the work domain was excluded, because, all study participants were students who do not engage in any moderate or vigorous work activities. The tool included many physical activity components, such as the frequency and duration of vigorous or moderate intensity along with a question regarding the number of hours spent in sedentary activities per day. METs (Metabolic Equivalents) are commonly used to express the intensity of physical activities and it was used for the analysis of GPAQ data. The score is assessed as an equivalent combination of moderately and vigorously intense physical activity, and students who achieved a minimum of 600 MET minutes for a week.

\section{Lifestyle Questionnaire}

The lifestyle questionnaire including components such as diet, sleep, and mental health of the university students, was used before and during the COVID-19 lockdown. The dietary assessment was performed with food frequency questionnaire $^{35}$ developed by the Saudi Food and Drug Administration (SFDA), in this study for both time points; Initially, through direct face-to-face interview, the data was obtained. However, during COVID-19, it was obtained through telecommunication interviews. ${ }^{36} \mathrm{~A}$ total list of 140 food items was included in the questionnaire with closed-ended questions, where consumption frequency choices were stated as the following: never or less than a month, once a week, two to four times per week, five to six times per week, once a day, two to three times per day, four to five times per day, more than 5 times per day. Open-ended questions were included in the questionnaire to collect information about unlisted food items. PSQI ${ }^{37}$ was used to assess sleep quality before and during the lockdown. The tool contains 7 components, encompassing 19 questions of self-evaluation, consisting of subjective sleep quality, sleep latency, sleep duration, sleep efficiency, sleep disturbances, sleeping medication, and daytime dysfunction. The score for each component can range from zero indicating no difficulty to three indicating severe difficulty. The sum of the seven components gives the total PSQI score between zero and 21 points. The students who scored greater than five considered poor sleepers while those with a PSQI score equal to or less than five considered good sleepers. The PSS ${ }^{38}$ is one of the most common scales used to assess the stress level of different population groups, consists of 10 items, including six negative and four positive. The scale measures depression, anxiety, and perception of poor health, as well as decreased satisfaction with self, job, and life in general, which are different 
psychosocial measures. Each item is rated on a 5-point scale from never scored zero to very often scored four. The students got a higher score, which indicated the higher perceived stress. Total scores range from 0 to 40 , in which 0-13 indicating low stress, 14-26 indicating moderate stress, and $27-40$ corresponding severe stress. The questionnaire was piloted among 12 students, and they were excluded from the analysis. The reliability of the tool was tested $(r=0.968)$ using Cronbach's alpha after obtaining validity.

\section{Data Analyses}

The study was analyzed by using the Statistical Package for Social Sciences (SPSS), version 21.0, Armonk, New York: International Business Machines (IBM) Corporation. The normality of each quantitative variable was tested before analysis. The numbers and percentages were tabulated in the form of a frequency distribution by using descriptive analysis for categorical variables. Results were presented as mean \pm SD for continuous variables with $95 \%$ confidence interval. The BMI before and during lockdown was compared using the " $\mathrm{t}$ " test. Chi-square analysis was used to test the association between baseline information and BMI among students. The results on the level of $p<0.05$ were fixed for statistical significance.

\section{Results}

\section{Baseline Information of the Students}

Table 1 displays the basic sociodemographic information of students, which included age in years, gender, year of study, marital status, family type, and source of health information. A total number of 628 students in the bachelor program responded to the survey, in which 445 (70.9\%) were females, 194 (30.9\%) were the first year and $188(29.9 \%)$ were the second year of college level. Among them, 228 (36.3\%) were in the age of 18-19 years. The mean age score was $20.45 \pm 1.93$ years. The results also showed that $437(69.6 \%)$ and $191(30.4 \%)$ of the students were single and married, respectively. Most of the students $311(49.5 \%)$ belonged to a simple family. Regarding the time spent on social media, 292 (46.5\%) of them used 1 to 2 hours and 167 (26.6\%) of them used 5 or more than 5 hours daily.

\section{Anthropometric Data of the Students}

The bodyweight of the students showed that $32 \%$ increased their weight, $22 \%$ lost their weight, and approximately half
Table I Baseline Information of the Students. $(n=628)$

\begin{tabular}{|l|l|c|}
\hline Characteristic & Category & N (\%) \\
\hline Age (years) & $18-19$ & $228(36.3)$ \\
& $20-2 \mid$ & $206(32.8)$ \\
& $22-23$ & $130(20.7)$ \\
& 24 and Above & $64(10.2)$ \\
\hline Gender & Male & $183(29.1)$ \\
& Female & $445(70.9)$ \\
\hline Year of the study & Ist year & $194(30.9)$ \\
& 2nd year & $188(29.9)$ \\
& 3 rd year & $154(24.5)$ \\
& 4 th year & $92(14.7)$ \\
\hline Marital Status & Single & $437(69.6)$ \\
& Married & $191(30.4)$ \\
\hline Family type & Campus & $71(11.3)$ \\
& Simple family & $311(49.5)$ \\
& Joint family & $246(39.2)$ \\
\hline Time spent on social media/day & $<$ l hour & $43(6.8)$ \\
& I-2 hours & $292(46.5)$ \\
& $3-4$ hours & $126(20.1)$ \\
& 5 and above & $167(26.6)$ \\
\hline
\end{tabular}

Abbreviations: N, number; \%, percentage.

of the participants (46\%) maintained the same weight during COVID-19 lockdown when comparing to before lockdown. Regarding BMI, underweight decreased from $13.1 \%$ to $11.6 \%$, and obesity decreased from $7.4 \%$ to $6.4 \%$ during the lockdown. However, the normal BMI rate increased from $53.5 \%$ to $55.1 \%$, and overweight increased from $26 \%$ to $26.9 \%$ (Figure 1). There was statistical significant $(\mathrm{P}<0.001)$ association found between changes in parameters before and during lockdown with the weight gain and weight loss groups (Table 2).

\section{Physical Activity of the Students}

The mean and standard deviation (SD) of sedentary time (minutes) used daily by the students were $448.7 \pm 73.6$ and $517.8 \pm 83.03$ before and during lockdown respectively, which was significant $(p=0.0001)$. GPAQ score (MET-min /week) was $1116.5 \pm 125.3$ before lockdown and $1149.2 \pm$ 120.08 during the lockdown, which was also significant $(p=0.0001)$. The GPAQ $\geq 600$ MET-min/week was recommended by 327 (52.1\%) before lockdown and 301 (47.9\%) during the lockdown, proved statistical significance $(p<0.05)$ (Table 3). Most of the students $(68 \%)$ who maintained the same weight recommended GPAQ $\geq 600$ MET$\mathrm{min} /$ week during the lockdown. 


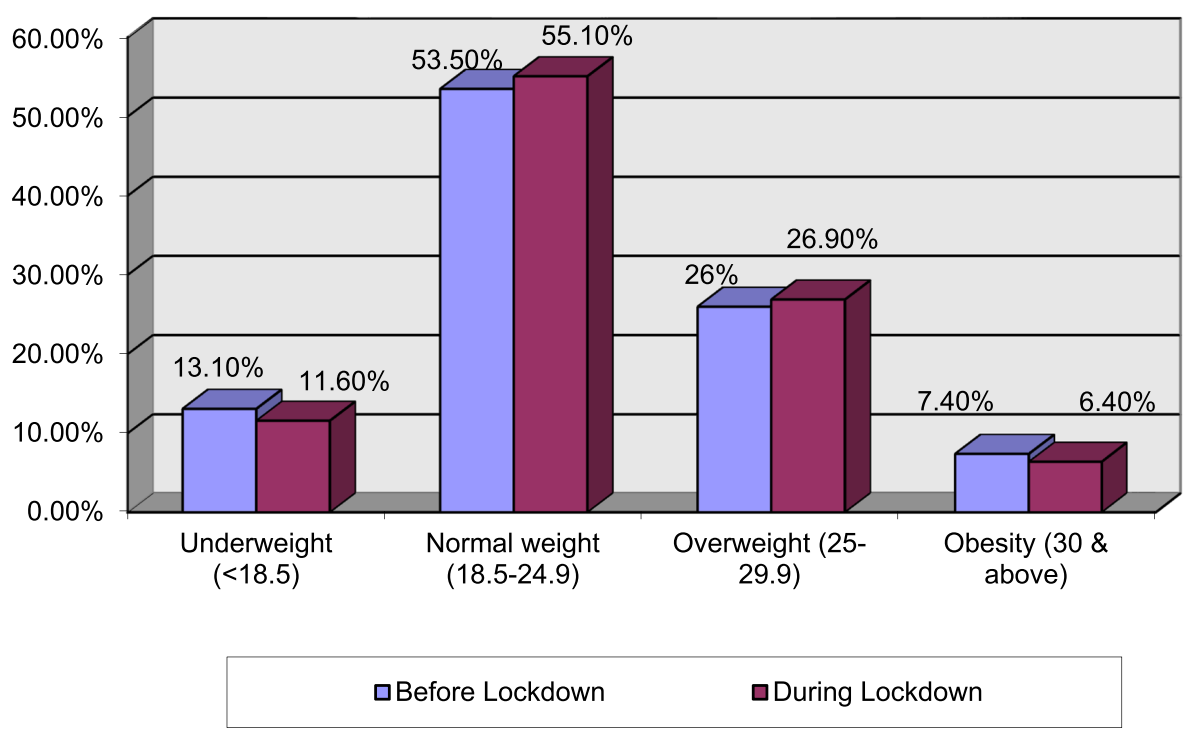

Figure I BMI of the students before and during COVID-19 lockdown.

\section{Lifestyle of the Students}

The lifestyle tool components including diet, sleep, and mental health of the university students, before and during the COVID-19 lockdown results were shown in Table 4. In the dietary recall assessment, $569(90.6 \%)$ and 341
(54.3\%) students were taken fast food consumption before and during lockdown respectively. Similarly, 547 (87.1\%) and $321(51.1 \%)$ were taken fried food consumption before and during lockdown respectively. The PSQI scores significantly $(p=0.001)$ decreased from $6.8 \pm 3.1$ to $5.9 \pm$

Table 2 Comparison of Weight Changes and Parameters Before and During Lockdown

\begin{tabular}{|c|c|c|c|c|c|c|}
\hline \multirow[t]{2}{*}{ Parameters } & \multicolumn{3}{|c|}{ Weight Gain $(n=200)$} & \multicolumn{3}{|c|}{ Weight Loss $(n=139)$} \\
\hline & Before Lockdown & During Lockdown & $P$ value & Before Lockdown & During Lockdown & $P$ value \\
\hline \multicolumn{7}{|c|}{ Physical activity parameters } \\
\hline Sedentary time (min/day) & $458.6 \pm 79.82$ & $524.1 \pm 89.16$ & $0.0001 * * *$ & $507.7 \pm 85.21$ & $439 \pm 72.38$ & $0.0001 * * *$ \\
\hline GPAQ score & $1122.7 \pm 129.42$ & $1082 \pm 114.86$ & $0.0001 * * *$ & $1146.1 \pm 115.87$ & $1122.7 \pm 129.42$ & $0.0576 \mathrm{NS}$ \\
\hline \multicolumn{7}{|l|}{ Dietary parameters } \\
\hline Energy (kcal/day) & $2987.6 \pm 196.71$ & $3021.5 \pm 150.94$ & $0.0001 * * *$ & $2651.6 \pm 116.67$ & $2635.8 \pm 75.21$ & 0.0742 INS \\
\hline Carbohydrate (g/day) & $324.2 \pm 13.6$ & $330.7 \pm 14.26$ & $0.0001 * * *$ & $316.4 \pm 5.5$ & $314.2 \pm 9.56$ & $0.0031 *$ \\
\hline Protein (g/day) & $50.1 \pm 5.8$ & $50.7 \pm 5.96$ & $0.0001 * * *$ & $46.8 \pm 4.37$ & $47.3 \pm 4.71$ & $0.00156^{*}$ \\
\hline Fat (g/day) & $148.7 \pm 17.16$ & $143.7 \pm 13.8$ & $0.000 I * * *$ & $178.4 \pm 4.14$ & $176.8 \pm 10.21$ & $0.03493 *$ \\
\hline Fast food consumption & $180(28.6)$ & $108(17.2)$ & $0.0001 * * *$ & $125(19.9)$ & 75 (II.9) & $0.0001 * * *$ \\
\hline Fried food consumption & $174(27.7)$ & $102(16.2)$ & $0.000 \mathrm{I} * * *$ & $120(19.1)$ & $66(10.5)$ & $0.000 \mathrm{I} * * *$ \\
\hline \multicolumn{7}{|l|}{ Sleep parameters } \\
\hline PSQI score & $7.2 \pm 1.26$ & $6.5 \pm 1.05$ & $0.0001 * * *$ & $6.4 \pm 1.05$ & $6.3 \pm 1.21$ & $0.59803 \mathrm{NS}$ \\
\hline \multicolumn{7}{|c|}{ Mental health parameters } \\
\hline PSS-10 score & $19.1 \pm 2.89$ & $15.5 \pm 1.43$ & $0.0001 * * *$ & $19.9 \pm 2.89$ & $19.1 \pm 3.3$ & $0.00209 *$ \\
\hline
\end{tabular}

Notes: *Significance at $p<0.05 ; * * *$ significance at $p<0.001$.

Abbreviation: NS, non-significant. 
Table 3 Comparison of Physical Activity of the Students Before and During Lockdown. $(n=628)$

\begin{tabular}{|c|c|c|c|c|}
\hline \multicolumn{2}{|l|}{ Parameters } & \multirow{2}{*}{$\begin{array}{l}\text { Before Lockdown } \\
448.7 \pm 73.6\end{array}$} & \multirow{2}{*}{$\begin{array}{l}\text { During Lockdown } \\
517.8 \pm 83.03\end{array}$} & \multirow{2}{*}{$\frac{P \text { value }}{0.0001^{* * *}}$} \\
\hline Sedentary time ( $\mathrm{min} /$ day) & Mean \pm SD & & & \\
\hline GPAQ score (MET-min/week) & & $1149.2 \pm 120.08$ & $1116.5 \pm 125.3$ & $0.000 \mathrm{I} * * *$ \\
\hline \multirow[t]{2}{*}{ Recommended GPAQ $\geq 600$ MET-min/week } & Yes & $327(52.1 \%)$ & $301(47.9 \%)$ & \multirow[t]{2}{*}{$0.0319 *$} \\
\hline & No & $289(46.1 \%)$ & $339(53.9 \%)$ & \\
\hline
\end{tabular}

Notes: *Significance at $p<0.05 ; * * *$ significance at $p<0.001$.

Table 4 Comparison of Lifestyle of the Students Before and During Lockdown. $(n=628)$

\begin{tabular}{|c|c|c|c|c|c|}
\hline Components & Parameters & & Before Lockdown & During Lockdown & $P$ value \\
\hline \multirow[t]{8}{*}{ Diet } & \multirow{4}{*}{\multicolumn{2}{|c|}{$\begin{array}{l}\text { Energy (kcal/day) } \\
\text { Carbohydrate (g/day) } \\
\text { Protein (g/day) } \\
\text { Fat (g/day) }\end{array}$}} & $2876.4 \pm 158.2$ & $2684.3 \pm 172.6$ & $0.001 * *$ \\
\hline & & & $328.6 \pm 33.8$ & $303.8 \pm 26.6$ & $0.001 * *$ \\
\hline & & & $49.2 \pm 12.8$ & $51.4 \pm 16.7$ & $0.001 * *$ \\
\hline & & & $150.8 \pm 128.0$ & $123.6 \pm 86.6$ & $0.001 *$ \\
\hline & \multirow[t]{2}{*}{ Fast food consumption } & Yes & $569(90.6)$ & $34 \mid(54.3)$ & $0.001 * *$ \\
\hline & & No & $59(9.4)$ & $287(45.7)$ & \\
\hline & \multirow[t]{2}{*}{ Fried food consumption } & Yes & $547(87.1)$ & $321(5 I .1)$ & $0.001 * *$ \\
\hline & & No & 81 (12.9) & $307(48.9)$ & \\
\hline \multirow[t]{3}{*}{ Sleep } & \multicolumn{2}{|l|}{ PSQI score } & $6.8 \pm 3.1$ & $5.9 \pm 2.8$ & $0.001 * *$ \\
\hline & \multirow[t]{2}{*}{ Sleep quality } & Good & $188(29.9)$ & $126(20.1)$ & $0.001 * *$ \\
\hline & & $\mathrm{Bad}$ & $440(70.1)$ & $502(79.9)$ & \\
\hline \multirow[t]{2}{*}{ Mental health } & \multirow{2}{*}{\multicolumn{2}{|c|}{$\begin{array}{l}\text { PSS-10 score } \\
\text { Total sleeping time (hour/day) }\end{array}$}} & $21.6 \pm 5.8$ & $17.4 \pm 6.7$ & $0.003 *$ \\
\hline & & & $6.6 \pm 2.3$ & $8.3 \pm 2.7$ & $0.001 * *$ \\
\hline
\end{tabular}

Notes: *Significance at $p<0.05 ; * *$ significance at $p<0.01$.

2.8 during lockdown when comparing with before lockdown (Table 4). Approximately, 188 (29.9\%) students felt that sleep quality was good before lockdown, and 126 (20.1\%) students felt the same during the lockdown. The PSS-10 score revealed that there was a statistically ( $p=$ 0.003 ) decreased from $21.6 \pm 5.8$ to $17.4 \pm 6.7$ during the lockdown. Moreover, the total sleeping time increased from $6.6 \pm 2.3$ hours per day to $8.3 \pm 2.7$ hours per day, which was also proved statistically significant $(p=0.001)$. The chi-square test proved that there was a significant association between the BMI during lockdown with the level of students $(\mathrm{p}<0.05)$ and time spent on social media per day $(\mathrm{p}<0.0001)$ (Table 5).

\section{Discussion}

The primary purpose of this prospective study was to assess the changes in body weight, BMI, physical activity, and lifestyle and their association with COVID-19 lockdown among the university students of Saudi Arabia. Out of 628 students, $29.1 \%$ were boys and $70.9 \%$ were girls. Eventhough, most of the students were girls, there was no significant association found between BMI and gender differences. Among them, the mean score of age with SD was $20.45 \pm 1.93$ and most of the participants in this study $(69.6 \%)$ were unmarried. The frequency of overweight increased from $16.6 \%$ to $17.8 \%$, and obesity was increased from $10.2 \%$ to $11.3 \%$. A similar cross-sectional study was conducted among Polish women, ${ }^{39}$ of which most women gained weight, while few of them reduced weight during the study period of the COVID-19 pandemic. The chi-square test proved that there was a significant association between BMI (weight changes) during lockdown with the level of students $(\mathrm{p}<0.05)$ and time spent on social media per day $(\mathrm{p}<0.0001)$. A study on nutrition behaviors in Polish adults before and during COVID-19 lockdown, in which two-thirds of the participants proved significant body weight changes, among them, half of the Polish adults were overweight during 
Table 5 Association of Weight Changes and Baseline Information of the Students During Lockdown. $(n=628)$

\begin{tabular}{|c|c|c|c|c|c|}
\hline Characteristic & Category & Weight Gain & Weight Loss & No Weight Changes & Chi-Square test \\
\hline \multirow[t]{4}{*}{ Age (years) } & $18-19$ & 75 & 54 & 99 & $X^{2}=2.3261$ \\
\hline & $20-21$ & 63 & 42 & 101 & $p=0.887403 \mathrm{NS}$ \\
\hline & $22-23$ & 42 & 31 & 57 & \\
\hline & 24 and Above & 20 & 12 & 32 & \\
\hline \multirow[t]{2}{*}{ Gender } & Male & 66 & 38 & 79 & $x^{2}=2.1174$ \\
\hline & Female & 134 & 101 & 210 & $p=0.346909 \mathrm{NS}$ \\
\hline \multirow[t]{4}{*}{ Year of the study } & Ist year & 50 & 49 & 95 & $X^{2}=14.1702$ \\
\hline & 2nd year & 61 & 36 & 91 & $p=0.027792 *$ \\
\hline & 3 rd year & 48 & 41 & 65 & \\
\hline & 4th year & 41 & 13 & 38 & \\
\hline \multirow[t]{2}{*}{ Marital Status } & Single & $|3|$ & 96 & 210 & $X^{2}=2.8896$ \\
\hline & Married & 69 & 43 & 79 & $p=0.23579 \mathrm{NS}$ \\
\hline \multirow[t]{3}{*}{ Family type } & Campus & 19 & 15 & 37 & $X^{2}=8.0562$ \\
\hline & Simple family & 89 & 67 & 155 & $p=0.089541 \mathrm{NS}$ \\
\hline & Joint family & 92 & 57 & 97 & \\
\hline \multirow[t]{4}{*}{ Time spent on social media/day } & $<1$ hour & 8 & 15 & 20 & $X^{2}=55.7124$ \\
\hline & I-2 hours & 106 & 52 & 34 & $p=0.000 I^{* * *}$ \\
\hline & $3-4$ hours & 42 & 29 & 55 & \\
\hline & 5 and above & 44 & 43 & 80 & \\
\hline
\end{tabular}

Notes: *Significance at $p<0.05 ; * * *$ significance at $p<0.001$.

Abbreviation: NS, non-significant.

the lockdown. ${ }^{40}$ This was supported by the BMI status of the students which was associated with the weight gain of participants. Those students with higher BMI gained more weight, which was often compared to those students who had normal BMI. ${ }^{41}$

Many kinds of researches indicated that college student's physical activities were reduced during the lockdown period. ${ }^{42-46}$ In the present study, the mean and SD of sedentary time (minutes) used daily by the students were $448.7 \pm 73.6$ and $517.8 \pm 83.03$ before and during lockdown respectively, which was significant $(\mathrm{p}=0.0001)$. GPAQ score (MET-min/week) was $1116.5 \pm 125.3$ before lockdown and $1149.2 \pm 120.08$ during the lockdown, which was also significant $(\mathrm{p}=0.0001)$. The study was done among UK adults on the obesity, eating behavior, and physical activity during COVID-19 lockdown, which results were predictive of greater overeating and lower physical activity in lockdown. ${ }^{47}$

Another study aimed to assess changes in obesity and activity patterns among youths during the pandemic lockdown in China. This study results proved that there were significant changes, including the decreased frequency of engaging in active transport, moderate or vigorous and highintensity housework, physical activity during leisure time, walking during leisure time, and there was increased sedentary, sleeping, and screen time. ${ }^{48}$ An Italian survey was conducted to assess the impact of the pandemic on eating habits and lifestyle changes during COVID-19 lockdown, which indicated that weight gain was observed among half of the population and there was a slight increase in physical activity. ${ }^{49}$ However, in the current study in Saudi, most students 436 (69.4\%) were spent time in sitting at one place for a longer period. And $24.5 \%$ were eaten snacks between meals all day and $23 \%$ were preferred to eat junk foods for meals always and $31.4 \%$ were likely to eat fast foods and fried foods for meals sometimes. Some other studies also witnessed that there was an association between the BMI with less frequent consumption of good nutrient foods like vegetables, fruits, and legumes during the lockdown, and higher adherence to meat, dairy, and fast foods. ${ }^{50}$ An observational retrospective study was done in northern Italy resulting that there was a significant association between increased weight gain and not consuming healthy foods and individuals with obesity significantly gained weight one month after the beginning of the quarantine. ${ }^{51}$

About the rest and sleep pattern in a pandemic, ${ }^{42}$ an online survey was conducted to assess the impact of lockdown on the sleep-wake pattern, meal timings, and digital 
media exposure time of the Indian population during the lockdown. The analysis evidenced that the sleep onset and wakeup time and meal-time was significantly delayed during the lockdown, which was highly pronounced in younger participants. $^{52}$ In the current study, the PSQI scores decreased significantly ( $p=0.001$ ) from $6.8 \pm 3.1$ to $5.9 \pm$ 2.8 during lockdown when comparing with before lockdown.

A longitudinal observational study located in Verona, Italy, conducted to determine the effects of COVID-19 lockdown on lifestyle behaviors in children with obesity proved that the time spent in sports activities decreased in children $(p=0.003)$, and sleep time increased $(p=0.003)$ and the watching of screen time also increased per day ( $p$ $<0.001) .^{25,53}$ In this research, regarding the time spent on social media, $292(46.5 \%)$ of them used 1 to 2 hours and $167(26.6 \%)$ of them used 5 or more than 5 hours daily.

This study derives strengths in the high power of the sample and fair representation of students from different colleges. This study aimed to associate BMI with physical activity and lifestyle at the college level. Though it is pandemic, we could able to collect the data. The tool was validated by experts and reliability was tested through a pilot study. The findings are obtained through sound analysis by using the software. However, the study has some limitations. The anthropometric measurements at a second point of time were assessed by the students. There were more females than males who participated in the study, which might impact the findings of association. There could be recall bias while collecting lifestyle components. Also, the design of the research did not permit causal inferences in the results. In the future, the study could be involved post-graduate students to assess their BMI changes in such kind of pandemic lockdown.

\section{Conclusion}

Though half of the students maintain the same BMI in lockdown, the students increased BMI which was associated with physical and lifestyle factors. Interestingly, among the students who reduced weight may be attributed by reduced intake of fast and fried food during the COVID-19 lockdown. Poor physical activity was reported by many students and most of them using a sedentary lifestyle. It is an alarming report for us to take measures to reduce obesity prevalence. Hence, health awareness such as weight maintenance, active physical activities, a healthy lifestyle including a balanced diet, adequate sound sleep, active and stress-free mental status must be created among the students, which help in creating and implementing policies in the future.

\section{Abbreviations}

BMI, body mass index; COVID-19, corona virus disease; GPAQ, global physical activity questionnaire; KSA, Kingdom of Saudi Arabia; METs, Metabolic Equivalents; NIH, national institute of health; PSQI, Pittsburgh sleep quality index; PSS, perceived stress scale; SD, standard deviation; WHO, World Health Organization.

\section{Acknowledgments}

The authors extend their appreciation to the Deanship of Scientific Research at King Faisal University, Al-Ahsa, Kingdom of Saudi Arabia for its financial support through Nasher track with reference to the research grant number 206130.

\section{Disclosure}

The authors report no conflicts of interest in this work.

\section{References}

1. Garry S, Abdelmagid N, Baxter L, et al. Considerations for planning COVID-19 treatment services in humanitarian responses. Confl Health. 2020;14:80. doi:10.1186/s13031-020-00325-6

2. Lippi G, Henry BM, Bovo C, Sanchis-Gomar F. Health risks and potential remedies during prolonged lockdowns for coronavirus disease 2019 (COVID-19). Diagnosis. 2020;7:85-90. doi:10.1515/dx2020-0041

3. Lopez-Bueno R, Calatayud J, Casana J, et al. COVID-19 confinement and health risk behaviors in Spain. Front Psychol. 2020;11:1426. doi:10.3389/fpsyg.2020.01426

4. Ammar A, Brach M, Trabelsi K, et al. Effects of COVID-19 home confinement on eating behaviour and physical activity: results of the ECLB-COVID19 international online survey. Nutrients. 2020;12 (6):1583. doi: $10.3390 / n u 12061583$

5. Wang C, Pan R, Wan X, et al. A longitudinal study on the mental health of general population during the COVID-19 epidemic in China. Brain Behav Immun. 2020;87:40-48. doi:10.1016/j. bbi.2020.04.028

6. Rubin GJ, Wessely S. The psychological effects of quarantining a city. BMJ. 2020;368:m313. doi:10.1136/bmj.m313

7. Tornaghi M, Lovecchio N, Vandoni M, Chirico A, Codella R. Physical activity levels across COVID-19 outbreak in youngsters of Northwestern Lombardy. J Sports Med Phys Fitness. 2020. doi:10.23736/S0022-4707.20.11600-1

8. Gray CL, Messer LC, Rappazzo KM, Jagai JS, Grabich SC, Lobdell DT. The association between physical inactivity and obesity is modified by five domains of environmental quality in U.S. adults: a cross-sectional study. PLoS One. 2018;13:e203301. doi:10.1371/ journal.pone. 0203301

9. Bluher M. Obesity: global epidemiology and pathogenesis. Nat Rev Endocrinol. 2019;15:288-298. doi:10.1038/s41574-019-01768

10. Lavie CJ, Ozemek C, Carbone S, Katzmarzyk PT, Blair SN. Sedentary behavior, exercise, and cardiovascular health. Circ Res. 2019;124:799-815. doi:10.1161/CIRCRESAHA.118.312669

11. Caci G, Albini A, Malerba M, Noonan DM, Pochetti P, Polosa R. COVID-19 and obesity: dangerous liaisons. J Clin Med. 2020;9 (8):2511. doi:10.3390/jcm9082511 
12. Malik VS, Ravindra K, Attri SV, Bhadada SK, Singh M. Higher body mass index is an important risk factor in COVID-19 patients: a systematic review and meta-analysis. Environ Sci Pollut Res Int. 2020;27(33):42115-42123. doi:10.1007/s11356020-10132-4

13. Kim TS, Roslin M, Wang JJ, et al. BMI as a risk factor for clinical outcomes in patients hospitalized with COVID-19 in New York. Obesity. 2021;29(2):279-284. doi:10.1002/oby.23076

14. Metallinos-Katsaras E, Must A, Gorman K. A longitudinal study of food insecurity on obesity in preschool children. J Acad Nutr Diet. 2012;112:1949-1958. doi:10.1016/j.jand.2012.08.031

15. Pan L, Sherry B, Njai R, Blanck HM. Food insecurity is associated with obesity among US adults in 12 states. J Acad Nutr Diet. 2012;112:1403-1409. doi:10.1016/j.jand.2012.06.011

16. Vandoni M, Lovecchio N, Carnevale Pellino V, et al. Self-reported physical fitness in children and adolescents with obesity: a cross-sectional analysis on the level of alignment with multiple adiposity indexes. Children. 2021;8(6):476. doi:10.3390/ children 8060476

17. Kerkadi A, Sadig AH, Bawadi H, et al. The relationship between lifestyle factors and obesity indices among adolescents in Qatar. Int J Environ Res Public Health. 2019;16:4428. doi:10.3390/ ijerph16224428

18. Al-Rethaiaa AS, Fahmy AEA, Al-Shwaiyat NM. Obesity and eating habits among college students in Saudi Arabia: a cross sectional study. Nutr J. 2010;9:39. doi:10.1186/1475-2891-9-39

19. Chirico A, Lucidi F, Galli F, et al. COVID-19 outbreak and physical activity in the Italian Population: a cross-sectional analysis of the underlying psychosocial mechanisms. Front Psychol. 2020;11:2100. doi:10.3389/fpsyg. 2020.02100

20. Abdelhafez AI, Akhter F, Alsultan AA, Jalal SM, Ali A. Dietary practices and barriers to adherence to healthy eating among King Faisal University students. Int J Environ Res Public Health. 2020;17 (23):8945. doi:10.3390/ijerph17238945

21. Altenburg TM, Singh AS, van Mechelen W, Brug J, Chinapaw MJ. Direction of the association between body fatness and self-reported screen time in Dutch adolescents. Int $J$ Behav Nutr Phys Act. 2012;9:4. doi:10.1186/1479-5868-9-4

22. Ha SA, Lee SY, Kim KA, et al. Eating habits, physical activity, nutrition knowledge, and self-efficacy by obesity status in upper-grade elementary school students. Nutr Res Pract. 2016;10:597-605. doi:10.4162/nrp.2016.10.6.597

23. Al-Haifi AR, Al-Fayez MA, Al-Athari BI, et al. Relative contribution of physical activity, sedentary behaviors, and dietary habits to the prevalence of obesity among Kuwaiti adolescents. Food Nutr Bull. 2013;34:6-13. doi:10.1177/156482651303400102

24. Nakamura M, Shirai Y, Sakuma M. Dietary changes during the COVID-19 pandemic: a longitudinal study using objective sequential diet records from an electronic purchase system in a workplace cafeteria in Japan. Nutrients. 2021;13(5):1606. doi:10.3390/ nu13051606

25. Pietrobelli A, Pecoraro L, Ferruzzi A, et al. Effects of COVID-19 lockdown on lifestyle behaviors in children with obesity living in Verona, Italy: a longitudinal study. Obesity. 2020;28:1382-1385. doi:10.1002/oby.22861

26. Franckle R, Adler R, Davison K. Accelerated weight gain among children during summer versus school year and related racial/ethnic disparities: a systematic review. Preventing Chronic Disease. 2014;11:e101. doi:10.5888/pcd11.130355

27. Wang YC, Vine S, Hsiao A, Rundle A, Goldsmith J. Weight-related behaviors when children are in school versus on summer breaks: does income matter. $J$ Sch Health. 2015;85:458-466. doi:10.1111/ josh. 12274

28. Alhusseini N, Alqahtani A. COVID-19 pandemic's impact on eating habits in Saudi Arabia. J Public Health Res. 2020;9(3):1868. doi:10.4081/jphr.2020.1868
29. Romero-Blanco C, Rodríguez-Almagro J, Onieva-Zafra MD, ParraFernández ML, Prado-Laguna MDC, Hernández-Martínez A. Sleep pattern changes in nursing students during the COVID-19 lockdown. Int J Environ Res Public Health. 2020;17(14):5222. doi:10.3390/ ijerph 17145222

30. Wathelet M, Duhem S, Vaiva G, et al. Factors associated with mental health disorders among university students in France confined during the COVID-19 pandemic. JAMA Netw Open. 2020;3(10):e2025591. doi:10.1001/jamanetworkopen.2020.25591

31. Weir CB, Jan A. BMI classification percentile and cut off points. In: StatPearls [Internet]. Treasure Island (FL):StatPearls Publishing; 2021

32. Wannamethee SG, Shaper AG, Walker M. Overweight and obesity and weight change in middle aged men: impact on cardiovascular disease and diabetes. J Epidemiol Community Health. 2005;59 (2):134-139. doi:10.1136/jech.2003.015651

33. World Health Organization. Global physical activity questionnaire (GPAQ) analysis guide [internet]. World Health Organization; 2004. Available from: https://www.who.int/ncds/surveillance/steps/ resources/GPAQ_Analysis_Guide.pdf. Accessed July 7, 2021.

34. Alkahtani SA. Convergent validity: agreement between accelerometry and the global physical activity questionnaire in college-age Saudi men. BMC Res Notes. 2016;9(1):436.

35. Gosadi IM, Alatar AA, Otayf MM, et al. Development of a Saudi food frequency questionnaire and testing its reliability and validity. Saudi Med J. 2017;38(6):636-641. doi:10.15537/smj.2017.6.20055

36. Engelmann G, Marsall M, Skoda EM, et al. Development and validation of the general dietary behavior inventory (GDBI) in scope of international nutrition guidelines. Nutrients. 2021;13(4):1328. doi: 10.3390/nu13041328

37. Suleiman KH, Yates BC, Berger AM, Pozehl B, Meza J. Translating the Pittsburgh sleep quality index into Arabic. West J Nurs Res. 2010;32(2):250-268. doi:10.1177/0193945909348230

38. Cohen S, Williamson G. Perceived stress in a probability sample of the United States. In: Spacapan S, Oskamp S, editors. The Social Psychology of Health: Claremont Symposium on Applied Psychology. Newbury Park, CA, USA: Sage Publications; 1988:31-76.

39. Drywien ME, Hamulka J, Zielinska-Pukos MA, Jeruszka-Bielak M, Gornicka M. The COVID-19 pandemic lockdowns and changes in body weight among Polish women. A cross-sectional online survey PlifeCOVID-19 study. Sustainability. 2020;12(18):7768. doi:10.3390/ su 12187768

40. Blaszczyk-Bebenek E, Jagielski P, Boleslawska I, Jagielska A, Nitsch-Osuch A, Kawalec P. Nutrition behaviors in Polish adults before and during COVID-19 lockdown. Nutrients. 2020;12 (10):3084. doi:10.3390/nu12103084

41. Kriaucioniene V, Bagdonaviciene L, Rodríguez-Pére C, Petkeviciene J. Associations between changes in health behaviours and body weight during the COVID-19 quarantine in Lithuania: the Lithuanian COVIDiet study. Nutrients. 2020;12(10):3119. doi:10.3390/nu12103119

42. Lopez-Moreno M, Lopez M, Miguel M, Garces-Rimon M. Physical and psychological effects related to food habits and lifestyle changes derived from Covid- 19 home confinement in the Spanish population. Nutrients. 2020;12(11):3445. doi:10.3390/ nu12113445

43. Martinez-de-quel O, Suarez-Iglesias D, Lopez-Flores M, Perez CA. Physical activity, dietary habits and sleep quality before and during COVID-19 lockdown: a longitudinal study. Appetite. 2021;1 58:105019. doi:10.1016/j.appet.2020.105019

44. Reyes-Olavarria D, Latorre-Roman PA, Guzmán-Guzman IP, JerezMayorga D, Caamano-Navarrete F, Delgado-Floody P. Positive and negative changes in food habits, physical activity patterns, and weight status during COVID-19 confinement: associated factors in the Chilean population. Int J Environ Res Public Health. 2020;17 (15):5431. doi:10.3390/ijerph17155431 
45. Marchant G, Bonaiuto F, Bonaiuto M, Guillet Descas E. Exercise and physical activity ehealth in COVID-19 pandemic: a cross-sectional study of effects on motivations, behavior change mechanisms, and behavior. Front Psychol. 2021;12:618362. doi:10.3389/fpsyg.2021.618362

46. Leon-Zarceno E, Moreno-Tenas A, Boix Vilella S, García-Naveira A, Serrano-Rosa MA. Habits and psychological factors associated with changes in physical activity due to COVID-19 confinement. Front Psychol. 2021;12:620745. doi:10.3389/fpsyg.2021.620745

47. Robinson E, Boyland E, Chisholm A, et al. Obesity, eating behavior and physical activity during COVID-19 lockdown: a study of UK adults. Appetite. 2021;156:104853. doi:10.1016/j.appet.2020.104853

48. Yang S, Guo B, Ao L, et al. Obesity and activity patterns before and during COVID-19 lockdown among youths in China. Clin Obes. 2020;10(6):e12416. doi:10.1111/cob.12416

49. Di Renzo L, Gualtieri P, Pivari F, et al. Eating habits and lifestyle changes during COVID-19 lockdown: an Italian survey. J Transl Med. 2020;18(1):229. doi:10.1186/s12967-020-02399-5
50. Sidor A, Rzymski P. Dietary choices and habits during COVID-19 lockdown: experience from Poland. Nutrients. 2020;12(6):1657. doi:10.3390/nu12061657

51. Pellegrini M, Ponzo V, Rosato R, et al. Changes in weight and nutritional habits in adults with obesity during the "lockdown" period caused by the COVID-19 virus emergency. Nutrients. 2020;12 (7):2016. doi:10.3390/nu12072016

52. Sinha M, Pande B, Sinha R. Impact of COVID-19 lockdown on sleep-wake schedule and associated lifestyle related behavior: a national survey. $J$ Public Health Res. 2020;9(3):1826. doi:10.4081/jphr.2020.1826

53. Balanza-Martínez V, Atienza-Carbonell B, Kapczinski F, De Boni RB. Lifestyle behaviours during the COVID-19 - time to connect. Acta Psychiatr Scand. 2020;141:399-400. doi:10.1111/ acps. 13177
Journal of Multidisciplinary Healthcare

\section{Publish your work in this journal}

The Journal of Multidisciplinary Healthcare is an international, peerreviewed open-access journal that aims to represent and publish research in healthcare areas delivered by practitioners of different disciplines. This includes studies and reviews conducted by multidisciplinary teams as well as research which evaluates the results or conduct of such teams or healthcare processes in general. The journal

\section{Dovepress}

covers a very wide range of areas and welcomes submissions from practitioners at all levels, from all over the world. The manuscript management system is completely online and includes a very quick and fair peer-review system. Visit http://www.dovepress.com/testimonials. php to read real quotes from published authors. 